\title{
1. Innovation, Industry Engagement, and Entrepreneurship in Engineering Programs
}

\author{
Beth-Anne Schuelke-Leech ${ }^{*}$ \\ Mechanical, Automotive, and Materials Engineering, University of Windsor, \\ Windsor, Ont, Canada \\ basl@uwindsor.ca
}

\begin{abstract}
Engineering Innovation and Entrepreneurship have become priority areas in many engineering faculties. As of yet, there are little cross-program sharing of lessons or benchmarking. There is no consensus on how to integrate these subjects into the core curriculum. The purpose of the paper is to explore entrepreneurship and innovation within engineering faculties.
\end{abstract}

Keywords: Engineering Entrepreneurship; Industry Engagement; Engineering Curriculum

\section{Summary}

Engineers, scientists, and mathematicians are all trained very differently, with different professional conventions, standards, and methods. They conceptualize research problems differently and seek understanding in line with their academic training. They are fundamentally different in terms of how they approach their jobs, the type and amount of supervision they require, the type of recognition they desire, their orientation towards industrial and research application, and their personality traits $[1,2]$. They have different research styles and information needs [3]. Scientists tend to gather information and test hypotheses, whereas engineers rely on more selective iterations to develop understanding and new knowledge [4]. Traditionally, scientists have been concerned with discovering and explaining nature, whereas engineers have been much more focused on using their understanding to develop and make things $[5,6]$. This has led to the generalization that scientists are more interested in discovery, while engineers are more focused on application.

The principal form of technology transfer from universities to industry are through human capital [7]. That is, through university graduates. Another important source of technology transfer is through cooperative research and collaboration [8]. One of the major aims of U.S. Science and Technology policy since the 1980s has been to encourage technology transfer from universities to industry. Numerous laws, policies, and programs have been enacted to promote industry-university collaboration and industrial involvement. U.S. researchers have grown more favorable towards closer university-industry collaboration [9]. Thus, university-industry collaborations have become an increasingly popular way to transfer technology and to develop technologies for commercial applications.

Companies collaborate as a way to obtain access to new technologies and technical expertise [10]. University and government researchers participate in collaborations to promote technology transfer and to gain access to industrial knowledge [11]. Successful commercialization of university research typically requires the research to be directly involved in any further development [12]. However, they rarely have the entrepreneurial and business skills required to navigate the commercialization process. Thus, university-industry collaborations increase the likelihood of the successful development of commercial products from university research since private corporations are able to guide development with their market orientation, as opposed to researchers attempting to push a technology that is developed in a university laboratory without a clear concept of the marketable application for which it can be used [11].

However, collaborations between the sectors can bring the two different cultures into conflict and create barriers to success. Merger and acquisition failures are frequently blamed on an inability of the two organizational cultures to integrate [11]. The private sector is looking for ideas and readily applicable technology to incorporate into its operations and processes, while public sector researchers are often driven by the science itself and the quality of their work. Academics are motivated to disseminate their research into the scientific community in which they belong, while businesses are primarily concerned with control over knowledge [13]. Private enterprises are under the time constraints of a rapidly-moving marketplace, while academic researchers take a much longer view of research projects and collaborations [14]. Academics tend to want funding that will last long enough to get $\mathrm{PhD}$ students through their degree (3-5 years). Thus, there is a mismatch in goals and 
timelines between the academic community and industry.

Technology transfer activities are typically concentrated in a few departments, rather than being wide-spread $[15,16]$. There is substantial evidence that engineers are more oriented towards industry and the needs of industry than other STEM graduates. The majority of academic researchers do not engage with industry in any way. In a survey of academic researchers in STEM fields, only 34 percent of all researchers (556 researchers of the 1636 surveyed) spend any time working with industry. For these researchers, disciplinary differences are noticeable. Approximately half of all engineers spent some time working with industry (49.5 percent), while only 30.5 percent of life scientists, 22.2 percent of physical scientists, and 22.9 percent of mathematicians and computer scientists did [17]. Academic Engineers with PhDs are more likely to be actively involved in technology transfer, commercialization, and industry engagement than other STEM faculty members [17].

The majority of engineers graduating with $\mathrm{PhDs}$ find employment in industry (72.2\%), whereas, life scientists, physical scientists, and mathematicians are all less likely to work in industry after graduation (33.1\%, 64.8\%, and 59.0\% respectively) [18]. Engineers are more likely to believe that the real world applicability of the research should be a factor in government funding decisions [17].

This paper explores whether innovation and entrepreneurship are taught and discussed differently in engineering and business schools. To see if there is any difference in the content of entrepreneurship courses, syllabi were gathered from five different areas of entrepreneurship: (1) business entrepreneurship (24 syllabi); (2) technological entrepreneurship (20 syllabi); (3) engineering entrepreneurship (8 syllabi); (4) management of technology (17 syllabi); and (5) social entrepreneurship (12 syllabi).

The results show that Engineering Entrepreneurship is not simply Business Entrepreneurship or Technological Entrepreneurship. Business Entrepreneurship courses put much more emphasis on the business process, whereas engineering entrepreneurship courses emphasize engineering design, product development, and project management. Engineers have different needs and skills. Therefore, curriculum designed to increase entrepreneurship, intrapreneurship, and innovation, has to recognize these differences. Thus, simply putting engineers in general business entrepreneurship courses is unlikely to increase entrepreneurial activities. Instead, engineering-specific curriculum is needed.

\section{References}

[1] L. E. Danielson, Characteristics of Engineers and Scientists: Significant for their Motivation and Utilization. Ann Arbor, MI: University of Michigan Press, 1960.

[2] T. J. Allen, "Distinguishing Engineers from Scientists," in Managing Professionals in Innovation Organizations, R. Katz, Ed., ed Cambridge, MA: Ballinger Publishing, 1988, pp. 3-18.

[3] T. E. Pinelli, A. P. Bishop, R. O. Barclay, and J. M. Kennedy, "The Information-Seeking Behavior of Engineers," in Encyclopedia of Library and Information Science. vol. 52, A. Kent and C. M. Hall, Eds., ed New York, NY: Marcel Dekker, Inc., 1993, pp. 167-200.

[4] W. G. Vincenti, What Engineers Know and How They Know it: Analytical Studies from Aeronautical History. Baltimore, MD: Johns Hopkins University Press, 1990.

[5] M. F. Blade, "Creativity in Engineering," in Essays on Creativity in the Sciences, M. A. Coler, Ed., ed New York, NY: New York University Press, 1963, pp. 110-122.

[6] R. R. Ritti, The Engineer in the Industrial Corporation. New York, NY: Columbia University Press, 1971.

[7] N. M. Reddy and L. Zhao, "International technology transfer: A review," Research Policy, vol. 19, pp. 285-307, 1990.

[8] H. N. Abramson, J. Encarnação, P. P. Reid, and U. Schmoch, "Overview and Comparison," in Technology Transfer in the United States and Germany, H. N. Abramson, J. Encarnação, P. P. Reid, and U. Schmoch, Eds., ed Washington, DC: National Academy Press, 1997, pp. 1-60.

[9] Y. S. Lee, "Technology transfer and the research university: a search for the boundaries of university-industry collaboration," Research Policy, vol. 25, pp. 843-863, 1996.

[10] T. R. Behrens and D. O. Gray, "Unintended consequences of cooperative research: impact of industry sponsorship on climate for academic freedom and other graduate student 
outcome," Research Policy, vol. 30, pp. 179199, 2001.

[11] J. Zieminski and J. Warda, Paths to Commercialization: University Collaborative Research. Ottawa, CA: The Conference Board of Canada, 1999.

[12] A. N. Link, D. S. Siegel, and B. Bozeman, "An empirical analysis of the propensity of academics to engage in informal university technology transfer," Industrial and Corporate Change, vol. 16, pp. 641-655, 2007.

[13] E. H. Schein, "Organizational culture," Massachusetts Institute of Technology (MIT), Sloan School of Management, Cambridge, MA Working paper 2088-88, 1988.

[14] A. Link and D. S. Siegel, "Generating science-based growth: an econometric analysis of the impact of organizational incentives on university-industry technology transfer," The European Journal of Finance, vol. 11, pp. 169-181, 2005.

[15] J. G. Bruhn, "Interdisciplinary Research: A Philosophy, Art Form, Artifact or Antidote?," Integrative Psychological \& Behavioral Science, vol. 35, pp. 58-66, 2000.

[16] J. Bercovitz and M. P. Feldman, "Technology Transfer and the Academic Department: Who Participates and Why?," presented at the DRUID Summer Conference 2003 on Creating, Sharing, and Transferring Knowledge, Copenhagen, 2003.

[17] B.-A. Schuelke-Leech, "Strangers in a Strange Land: Industry and Academic Researchers, PhD Dissertation," PhD, Public Administration and Policy, Public Administration and Policy, University of Georgia, Athens, GA, 2011.

[18] National Science Foundation. (2014, November 11, 2016). Science and Engineering Doctorates. Available: https://www.nsf.gov/statistics/2016/nsf1630 0/data-tables.cfm 